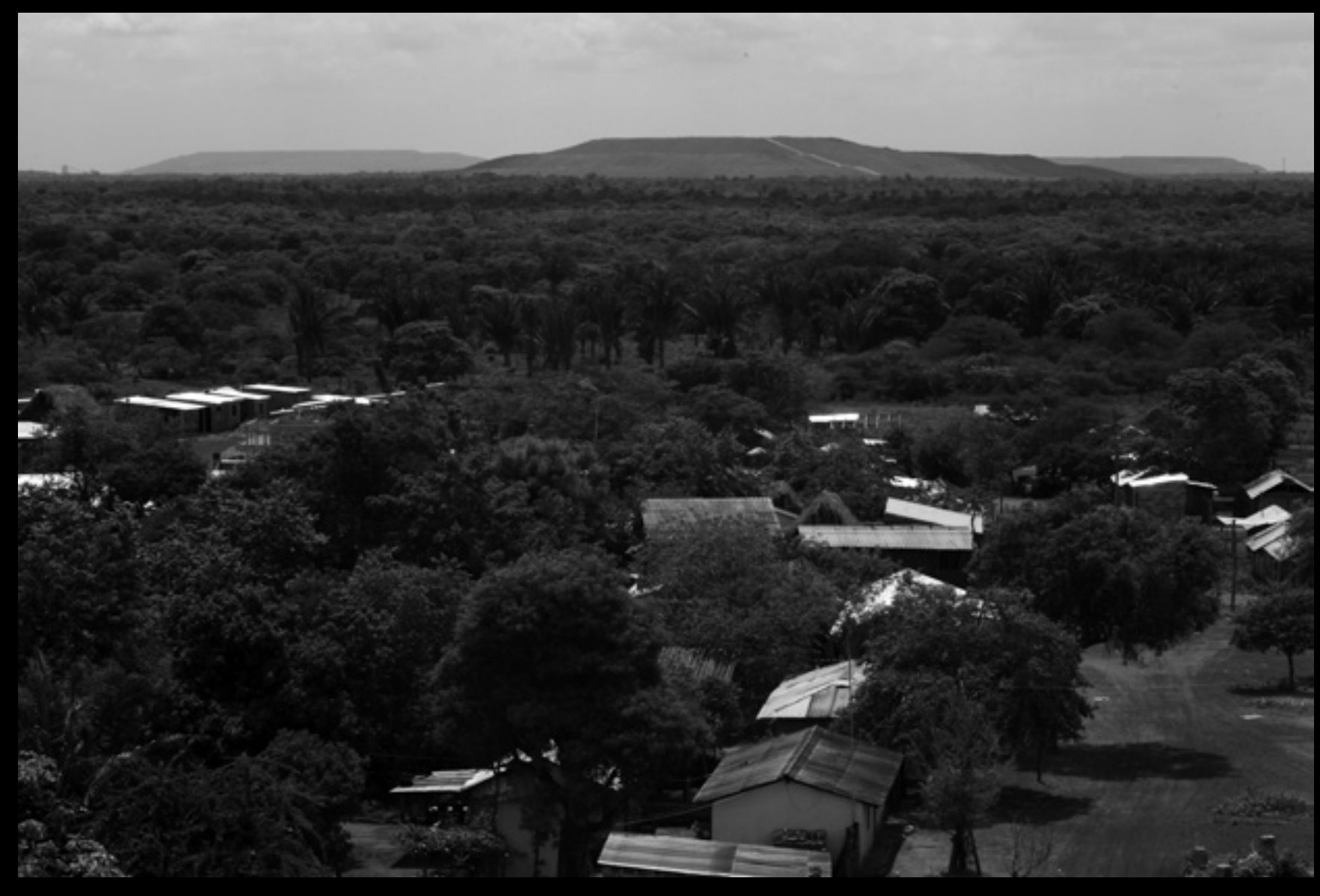

Las minas de carbón desde la perspectiva de la comunidad de Boquerón. Foto tomada por Freddy Bayona de la Fundación Chasquis. 2014 


\section{Historizar el lugar para resistir el desplazamiento por minería de carbón: una aproximación teórica al caso de la comunidad de Boquerón en el Cesar Historicizing the Place to Resist Coal Mining Displacement: a Theoretical Approach to the Case of the Boqueron Community in Cesar Historizar o local para resistir o deslocamento por mineração de carvão: aproximação teórica ao caso da comunidade de Boquerón em Cesar}

\section{Ximena González}

Centro de Estudios para la Justicia Social «Tierra Digna». (Bogotá, Colombia) ximegoz@gmail.com

\section{Diego Melo}

Centro de Estudios para la Justicia Social «Tierra Digna». (Bogotá, Colombia) meloascencio@gmail.com
El artículo es una reflexión teórica basada en el trabajo de campo realizado por los autores entre julio de 2012 y agosto de 2014. Se realizaron ocho visitas a terreno a diferentes puntos del corredor minero, en especial a Boquerón, La Jagua de Ibirico, Becerril, La Loma y El Hatillo. Los viajes tuvieron una duración promedio de 5 días por visita.

\section{Resumen}

La minería de carbón a gran escala en la zona centro del Cesar ha desembocado en la degradación ambiental de los recursos que sostienen la vida y el desmantelamiento de algunas de las más emblemáticas prácticas culturales de la comunidad de Boquerón, una población en proceso de desplazamiento forzado desde 2010 debido a la contaminación atmosférica de la zona. Este artículo es una reconstrucción teórica del caso que 1) presenta a Boquerón como un lugar mediante la historización de la relación mutuamente constitutiva entre los ecosistemas naturales y las prácticas productivas, las festividades y las creencias de la comunidad; 2) establece cómo los regímenes de tenencia y uso de la tierra durante la segunda mitad del siglo $\mathrm{xx}$ permitieron la desterritorialización de Boquerón mediante el deterioro progresivo de los ecosistemas que daban sustento a la comunidad; 3) desarrolla algunos lineamientos para motivar a los sectores académicos nacionales para que contribuyan al establecimiento de una metodología crítica y multidimensional sobre los impactos producidos por la minería a gran escala. Al realizar una aproximación teórica al caso de Boquerón argumentamos que la historización de los lugares construidos por las comunidades locales es una estrategia fundamental para resistir los fenómenos de despojo y desplazamiento forzado intrínsecos al extractivismo en Colombia.

Palabras clave

desterritorialización; minería; lugar; extractivismo; territorio

\begin{abstract}
Large-scale coal mining in the downtown Cesar area has led to the environmental degradation of the resources that sustain life and the dismantling of some of the most iconic cultural practices of the community of Boqueron, a population that has faced forced displacement since 2010 due to air pollution in the area. This article is a theoretical reconstruction of the case that 1) presents Boqueron as a place through historicizing the mutually constitutive relationship between natural ecosystems and productive practices, festivals and the community beliefs; 2) establishes how tenure regimes and the land use during the second half of the TWENTIETH century allowed the Boqueron deterritorialization by the progressive deterioration of ecosystems that used to give sustenance to the community; 3 ) develops some guidelines for encouraging national academic sectors to contribute to the establishment of a critical and multidimensional methodology on the impacts of large-scale mining. When presenting a theoretical approach to the Boqueron's case, we argue that historicizing the places built by local communities is an essential strategy to resist the phenomena of dispossession and forced displacement in Colombia, which are intrinsic features of extractivism.
\end{abstract}

\section{Keywords}

deterritorialization; mining; place; extractivism; territory

\section{Resumo}

A mineração de carvão em grande escala na zona centro de Cesar desembocou na degradação ambiental dos recursos que sustêm a vida e o desarranjo de algumas das mais emblemáticas práticas culturais da comunidade de Boquerón, população em processo de deslocamento forçoso desde 2010 devido à contaminação atmosférica na zona. Este artigo é uma reconstrução teórica do caso que 1) apresenta Boquerón como um local mediante a historização do relacionamento mutuamente constitutivo entre ecossistemas naturais e práticas produtivas, as festividades e as crenças da comunidade; 2) estabelece como foi que regímenes de posse e uso da terra durante a segunda metade do século xx permitiram a desterritorialização de Boquerón mediante o deterioro progressivo dos ecossistemas que forneciam sustento à comunidade; 3) desenvolve algumas diretrizes para motivar os setores académicos nacionais para contribuírem ao estabelecimento de uma metodologia crítica e multidimensional sobre os impactos produzidos pela mineração em grande escala. Ao realizar uma aproximação teórica do caso de Boquerón argumentamos que a historização dos locais construídos pelas comunidades locais é estratégia fundamental para resistir os fenómenos de espoliação e deslocamento forçoso intrínsecos ao extrativismo na Colômbia.

\section{Palavras-chave}

desterritorialização; mineração; local; extrativismo; território 
Bueno, los intereses en Boquerón son infinitos, porque es que Boquerón tiene unas reservas carboniferas demasiado grandes. Ese es el motivo por el cual van a reasentar a Boquerón, porque al gobierno no les interesa que la gente se muera por contaminación. Es lo que menos les interesa [sic].

Lider comunitario de Boquerón ${ }^{1}$

El corredor minero del Cesar es un espacio receptor de las más extensas e intensas dinámicas de extracción minera en Colombia: ocho empresas extraen más de 40 millones de toneladas de carbón anuales de tan solo cinco municipios que no reciben los supuestos beneficios económicos de la actividad minera ${ }^{2}$. Uno de los efectos más críticos de esta dinámica se materializó en 2010 cuando el Ministerio de Ambiente decretó el «reasentamiento involuntario» de tres poblaciones del corredor carbonífero, fundamentado en el hecho de que los niveles de material particulado de carbón en la atmósfera superaban los límites máximos permisibles y ponían en riesgo la salud humana ${ }^{3}$. Así, la medida se sustenta bajo el deber constitucional del Estado de proteger la salud de sus ciudadanos. Sin embargo, la contaminación generada por la explotación masiva de carbón por actores transnacionales desde 1995 fue previsible desde que se aprobaron

1 Líder de la comunidad de Boquerón, entrevistado por los autores, Valledupar, 26 de agosto, 2014. Por motivos de seguridad, el presente artículo omite los nombres de las personas entrevistadas.

2 La zona carbonífera del Cesar comprende los municipios de Becerril, Agustín Codazzi, Chiriguaná, El Paso y la Jagua de Ibirico. En esta zona operan cuatro empresas filiales de la transnacional suiza Glencore/Xstrata (Prodeco, Carbones de la Jagua, Carbones del Cesar y Carbones del Tesoro), las transnacionales estadounidenses Drummond y Colombian Natural Resources, una empresa de la transnacional Vale Coal con sede en Brasil (Emcarbón-Diamond-Vale) y una empresa de la transnacional canadiense Pacific Coal (Norcarbón-Área la Divisa) indirectamente vinculada con la corporación Pacific Rubiales Energy. En 2013 la Contraloría General de la República demostró que la consolidación de la minería a gran escala en el centro de Cesar no se había traducido en beneficios económicos para los municipios aledaños. Ver Guillermo Rudas Lleras y Jorge Enrique Espitia Zamora, «La paradoja de la minería y el desarrollo. Análisis departamental y municipal para el caso de Colombia», en Contraloría General de la República, Minería en Colombia: Institucionalidad y territorio, paradojas y conflictos, (Bogotá: Imprenta Nacional de Colombia, 2013), 62.

3 Ver Camila Osorio, «Hay locomotora minera, pero no locomotora para la reubicación de los vecinos», La Silla Vacía [Bogotá], 11 de septiembre, 2011. http://lasillavacia.com/historia/hay-locomotora-minera-pero-no-locomotora-para-la-reubicacion-de-losvecinos-27427 (consultado el 20 de septiembre de 2014). los megaproyectos mineros, lo cual borra cualquier duda sobre el interés estratégico en la zona y deslegitima cualquier pretensión garantista de las autoridades ambientales del Estado ${ }^{4}$. En términos académicos, el Estado decretó lo que la antropología crítica denomina "transferencias poblacionales» ${ }^{5}$, es decir, la orden e intervención del Estado en la movilización masiva y operacionalizada de poblaciones a través de tecnologías burocráticas de despojo con el objetivo de satisfacer una organización territorial particular, imponer una nueva cultura económica, facilitar la extracción de recursos y alcanzar metas estratégicas, todas estas dentro de la lógica del desarrollo extractivista, un fenómeno que no se da exclusivamente en Colombia ${ }^{6}$.

El modo de producción y distribución en América Latina ha privilegiado en las últimas tres décadas el lucro acelerado para la empresa privada y se ha alejado de los intereses del ser humano y del ambiente del lugar ${ }^{7}$. Desde las políticas de ajuste estructural impulsadas por el Consenso de Washington en la década de los ochenta, pasando por la creación y aprobación de marcos normativos y planes de desarrollo orientados a la exportación de minerales globalmente demandados (oro, carbón, cobre, litio y coltán), América Latina se ha caracterizado por seguir la senda del extractivismo, un

4 Además de anotar que la transnacional estadounidense Drummond Ltda. comienza la explotación de carbón en 1995, Fierro Morales y López Camacho explican que ni los planes de manejo ambiental de los proyectos mineros, ni las licencias ambientales reglamentadas desde 1994 contemplan aspectos fundamentales para la protección de los ecosistemas colombianos. Julio Fierro Morales y René López Camacho, «Aportes a la conceptualización del daño ambiental y del pasivo ambiental por minería», en Contraloría General de la República, Minería en Colombia: Daños ecológicos y socioeconómicos y consideraciones sobre un modelo minero alternativo (Bogotá: Imprenta Nacional de Colombia, 2014), 79-186.

5 Lars Sofestad, «Anthropology, development, and human rights: the case of involuntary resettlement» citado por Margarita Serje, «Introducción a los debates sobre procesos y proyectos de reasentamiento», en Los dilemas del reasentamiento, ed. Margarita Serje y Stefano Anzellini (Bogotá: Universidad de los Andes, 2012), 19.

6 Sofestad, «Anthropology, development, and human rights»; Peter Linebaugh y Marcus Rediker, «La hidra de la revolución: marineros, esclavos y campesinos en la historia oculta del Atlántico» citados por Margarita Serje, «Introducción a los debates», 17-42.

7 Ignacio Gómez Montes y María Luisa Eschenhagen, «Conflictos socioambientales de la minería de oro y el rol del modelo económico dominante en América Latina», en Extractivismo minero en Colombia y América Latina, ed. Bárbara Göbel y Astrid Ulloa (Bogotá: Universidad Nacional de Colombia/Ibero-Amerikanisches Institut, 2014), 460. Además, el concepto geográfico y antropológico de lugar se refiere a las formaciones culturales y su relación con el espacio. 
concepto en ciencias sociales clave para entender las dinámicas contemporáneas de apropiación de la naturaleza y sus implicaciones sociopolíticas. Göbel y Ulloa describen el extractivismo como un modo de producción a gran escala orientado preferentemente a la exportación que 1) implica la instalación de enclaves transnacionales en áreas periféricas y 2) requiere de conocimientos y tecnologías específicas, además de marcos legales y financieros determinados, que no tienen en cuenta los riesgos sociales y ambientales de las dinámicas de crecimiento económico pero sí privilegian la acumulación de riqueza ${ }^{8}$.

Göbel y Ulloa aseguran que el extractivismo produce reconfiguraciones en el uso, control y significación del territorio, lo que modifica los espacios en los ámbitos local, regional, nacional y transnacional, y conlleva graves efectos colaterales como el acaparamiento de tierras, el desplazamiento de poblaciones y el solapamiento y fragmentación de las lógicas de relacionamiento con la naturaleza propias de los pueblos indígenas, afrodescendientes y campesinos9. Este es el caso del extractivismo en el departamento de Cesar; la minería de carbón a cielo abierto y gran escala ha creado un escenario de convergencia entre la generación diaria de impactos sinérgicos y acumulativos sobre los recursos que sostienen la vida (degradación ambiental $)^{10}$, la transformación profunda e irreversible del entorno natural y las prácticas culturales de las poblaciones aledañas a los proyectos mineros (desterritorialización) ${ }^{11}$.

8 Bárbara Göbel y Astrid Ulloa, «Colombia y el extractivismo en América Latina», en Extractivismo minero en Colombia y América Latina, ed. Bárbara Göbel y Astrid Ulloa (Bogotá: Universidad Nacional de Colombia/ Ibero-Amerikanisches Institut, 2014).

9 Bárbara Göbel y Astrid Ulloa, «Colombia y el extractivismo en América Latina», 16.

10 Los impactos acumulativos se refieren al efecto conjunto y agravado de la contaminación proveniente de varias minas, mientras que los impactos sinérgicos son la profundización de estos impactos acumulativos a lo largo del tiempo. Para una valoración detallada de los impactos producidos por la minería de carbón en estos municipios entre 1997 y 2009 ver Ministerio de Ambiente, Vivienda y Desarrollo Territorial y Universidad de los Andes, Valoración Económica Ambiental en la Zona Carbonífera del Cesar que comprende los municipios de Becerril, Agustín Codazzi, Chiriguaná, El Paso y La Jagua de Ibirico, (Bogotá: Universidad de los Andes, 2010). http://www.colombiapuntomedio.com/Portals/0/ Archivos2014/Drummond2014/Valorac_Econ_Amb-Zona_Carb_ Cesar_MAVDT.pdf (consultado el 1 de junio de 2014).

11 Ver como contexto del término Bernardo Mançano Fernandes, «Movimentos socioterritoriais y movimentos socioespaciais: contri-
Una de esas poblaciones desterritorializadas y en proceso de desplazamiento forzado es Boquerón, el lugar sujeto-objeto del presente artículo. En esta comunidad rural, la minería ha generado profundos cambios culturales que se expresan en la alteración de los hábitos de alimentación y de los espacios de relacionamiento social ante las limitaciones en el acceso y goce de los recursos naturales. Dichas limitaciones se deben al proceso progresivo de privatización y «empresarización» de la tierra, el cual ha restringido el ejercicio de la pesca, la agricultura, la cacería y la recolección. Paralelamente, los espacios de encuentro, celebración y festividad que creaban un ambiente folclórico, musical y alegre a la vida cotidiana del poblado perdieron sentido y dejaron de ser practicados con el paso de los años. Esto ocurrió con la fiesta del «muñequeo», por ejemplo, una celebración que partía de la elaboración de muñecos de pan en masa de almojábana que eran bautizados para que dos personas asumieran el compromiso de palabra de velar por su buen cuidado y que promovía relaciones de compadrazgo y fraternidad comunitaria ${ }^{12}$. Para mediados de la década de 2000 ya no existen los animales de monte que cazaban los boqueroneros, ni varias de las especies de peces que se pescaban, ni celebraciones tan emblemáticas del tejido sociocultural como la fiesta del «muñequeo».

El poblado de Boquerón fue fundado por cinco familias afrodescendientes originarias del municipio de Becerril del Campo, que arribaron a la zona entre 1886 y 1890 y se asentaron allí de forma permanente entre 1903 y 1904 en los albores de la Guerra de los Mil Días ${ }^{13}$. En otras palabras, el corregimiento ha establecido su vida comunitaria en relación con el entorno natural de la zona centro de Cesar desde finales del siglo xix. Si la comunidad ha podido subsistir por tantas décadas en el territorio, ¿por qué debe abandonar la zona debido a la toxicidad del aire desde 2010?

buição teórica para uma leitura geográfica dos movimentos sociais», Revista Nera, n. 6 (2005), 278. http://revista.fct.unesp.br/index.php/ nera/article/view/1460/1436 (consultado en octubre de 2014).

12 María Ximena González, «Transformaciones culturales y territoriales ocasionadas por la minería a gran escala: el caso de la comunidad de Boquerón (Cesar-Colombia)» (Tesis de maestría, Pontificia Universidad Javeriana, 2013), 48.

13 González, «Transformaciones culturales», 4. 
Las teorías estructuralistas han dilucidado algunas respuestas a esta pregunta basadas en el análisis de la clase social, específicamente al postular que los fenómenos que suceden en la escala local (como la degradación de la tierra y la deforestación) están directamente ligados con transformaciones en la economía política a nivel nacional y global ${ }^{14}$.

En el ámbito global, la transferencia de los costos medioambientales a las comunidades más marginalizadas está relacionada con la expansión del sistema-mundo moderno-colonial ${ }^{15}$, en particular con la teoría de la acumulación bajo el modo de producción capitalista desarrollada por Marx. Según esta perspectiva, «el capitalismo está abocado a expandirse mediante una intensificación de las relaciones en los centros de producción capitalista y una ampliación geográfica de dichas relaciones en el espacio» ${ }^{16}$. Debido a sus contradicciones internas, el capitalismo debe intensificar los deseos y las necesidades de las poblaciones (para así expandir sus redes de circulación mediante el intercambio de mercancías y penetrar cada vez más la vida social, convirtiendo las actividades humanas en «trabajo social abstracto» $)^{17}$. Sin embargo, esta teoría no «pretende predecir con exactitud dónde, cuándo y cómo se van a producir dichas intensificaciones; estas constituyen el tema de análisis históricos concretos» ${ }^{18}$. Frente a este escenario, el análisis de la transformación territorial de Boquerón se vuelve necesario no solo para mostrar dónde, cuándo y cómo se intensifican las relaciones comerciales o se expande espacialmente el capital, sino qué consecuencias especificas conllevan estas dinámicas para la vida de personas y grupos concretos ${ }^{19}$.

14 Kristina Dietz, «Researching Inequalities from a Socio-ecological Perspective», desiguALdades.net International Research Network on Interdependent Inequalities in Latin America, $\mathrm{n} .{ }^{\circ}$ 74 (2014): 11. http://www.desigualdades.net/Resources/Working_Paper/74-WP-Dietz-Online.pdf?1411372033 (consultado el 25 de noviembre de 2014).

15 Immanuel Wallerstein, The Capitalist World Economy: Essays (Cambridge: Cambridge University Press, 1979); Walter Mignolo, Local Histories/Global Designs. Coloniality, Subaltern Knowledges, and Border Thinking (Princeton: Princeton University Press, 2012), 19.

16 David Harvey, «La geografía de la acumulación capitalista: reconstrucción de la teoría marxiana», en Espacios de capital: Hacia una geografía crítica, trans. Cristina Piña Aldao (Madrid: Akal, 2007), 274.

17 Harvey, «La geografía», 274; Michael Hardt y Antonio Negri, Imperio (Buenos Aires: Paidós Surcos 3, 2005).

18 Harvey, «La geografía», 274.

19 Más aún, en épocas en las que se dice que la modernidad tiende a subsumir el lugar al espacio y a desterritorializar la vida social y
La expansión geográfica de las dinámicas de acumulación primitiva ${ }^{20}$ en las zonas cercanas a Boquerón es visible y empíricamente comprobable a través de nuevas tecnologías satelitales como Google Earth. Las imágenes digitales de los tajos mineros de carbón de la zona centro del departamento muestran la magnitud y la degradación de la capa orgánica y la proximidad de las pequeñas poblaciones que deben afrontar los residuos y emisiones tóxicas de la extracción. La intensificación del capitalismo, por otra parte, se ha venido produciendo gracias a dos fenómenos paralelos. El primero es que el incremento en las «necesidades» energéticas globales han impulsado la extracción carbonífera hasta los miles de millones de toneladas anuales exportadas por Colombia, lo que incrementa de forma geométrica los impactos ambientales sobre los territorios intervenidos. El segundo fenómeno es la pérdida de actividades autosostenibles como la agricultura, la pesca y la caza a raíz de la minería a gran escala. El fin de estas actividades ha forzado/inducido a miles de familias a hacer parte de circuitos de circulación de capital a través de la compra de alimentos producidos por la agroindustria, y a proletarizar su trabajo empleándose en compañías mineras u otros sectores económicos para poder acceder al papel-dinero que, además de convertir su esfuerzo en «trabajo social abstracto", les permite acceder a mercados en los cuales antes no era necesario participar.

En el ámbito nacional, situaciones como el inminente desplazamiento de Boquerón se dan porque, dependiendo de quién tiene el poder de expresar sus propios intereses y el conocimiento de quién es considerado legítimo, se regularán las relaciones de la sociedad con la naturaleza ${ }^{21} y$

ecológica, se hace más pertinente analizar las transformaciones territoriales y su impacto en la vida de comunidades específicas como Boquerón para poder entender los impactos de la minería a gran escala en toda su complejidad. Anthony Giddens, The Consequences of Modernity y Paul Virilio, Speed and Politics, citados por Arturo Escobar, Territorios de diferencia: Lugar, movimientos, vida, redes, trad. Eduardo Restrepo (Popayán: Envión Editores, 2010), 48-49.

20 Definida como aquella obtenida a través de la apropiación de la riqueza común (common wealth) o fuera del proceso de producción capitalista. Ver David Harvey, «El "nuevo" imperialismo: acumulación por desposesión», Socialist Register, n. 40 (2004): 113; Michael Hardt y Antonio Negri, Commonwealth (Cambridge: Harvard University Press, 2009), 137-138.

21 Dietz, «Researching Inequalities», 16 
se le transferirán los costos del cambio climático o la pérdida de biodiversidad a los sectores más marginalizados de la población nacional. En Colombia, la relación entre los proyectos de expansión económica y la afectación desproporcionada de poblaciones locales ha sido descrita por Margarita Serje con el concepto de reversión, según el cual la cultura dominante de un país determina discursivamente que las regiones periféricas y sus habitantes existen en función de la satisfacción de las necesidades de la «nación» y pueden ser utilizados como fuente de riqueza y como sitios en los cuales esa cultura dominante puede poner en marcha sus experimentos sociales ${ }^{22}$.

El proceso lleva el nombre de reversión pues los proyectos de expansión económica se autolegitiman usando el discurso de la «nación» y revierten los papeles: «se supone que las instituciones del Estado deben responder y ajustarse a las demandas y necesidades de la sociedad» pero en realidad las poblaciones «consideradas menores, por ser " $m i-$ noritarias", ilegales o desechables, [d] eben plegarse y convertirse en instrumento de los designios y necesidades del Estado, en cuanto representantes de una sociedad "mayor" de carácter virtual»" En relación con la minería en el centro de Cesar, el fenómeno es autoevidente pues la extracción carbonífera ha sido legitimada como actividad de «utilidad pública» y de «interés nacional y estratégico» en detrimento de la permanencia en el territorio de comunidades locales como Boquerón ${ }^{24}$.

No obstante estas apreciaciones teóricas, comunidades como Boquerón no deben ser vistas solo como nodos de un sistema capitalista global dada la importancia de la «política del lugar»" 25 Los cambios microsociales que se han dado a lo largo del proceso de devastación ambiental son cruciales para un análisis completo del extractivismo.

22 Margarita Serje, El revés de la nación, 2 ed. (Bogotá: Universidad de los Andes, 2011), 177.

23 Serje, El revés de la nación, 177-211.

24 Por medio del documento Conpes 3762 de 2013, el gobierno nacional formuló los lineamientos de política pública para el desarrollo de 51 proyectos de interés nacional y estratégicos para la nación (PINES), entre los cuales incluyó los proyectos de extracción de carbón en Cesar. La Agencia Nacional Minera emitió la Resolución 592 de 2013, por medio de la cual declara 40 proyectos mineros de interés nacional, entre los cuales se encuentran los proyectos mineros en Cesar.

25 Escobar, Territorios de diferencia, 79.
En Cesar, la llegada de la minería introdujo nuevos valores sociales inspirados en la búsqueda de oportunidades de ocupación para la obtención y acumulación de ingresos y activos. En Boquerón, las restricciones en las posibilidades comunales de acceso, uso y disfrute de la tierra y de los recursos naturales traídas por la minería transnacional, junto con la instalación de la propiedad privada como estructura predominante de relacionamiento con el territorio, transformaron no solo la disposición material de la tierra, pues esta no solo pasó a ser parcelada y subdividida, sino que dio lugar a nuevos anhelos personales y familiares sustentados en la idea de acumulación de bienes y dinero como sentido de la vida.

Frente a estas circunstancias debe priorizarse un entendimiento complejo de la situación anclado en conceptos como el lugar (las formaciones culturales y su relación con el espacio), la deslocalización (o cómo las fuerzas estructurantes del territorio -el capital, el Estado y la tecnocienciacambian la producción de la localidad en su favor sin respeto por las comunidades y conocimientos basados-en-lugar) y el territorio-región (categoría que vincula la noción de territorio con el proyecto de vida de la comunidad que lo habita y sus conocimientos ecoculturales en clave de sustentabilidad ${ }^{26}$. De esta manera, proponemos un estudio riguroso de las implicaciones teóricas que presenta el caso de Boquerón para la historiografía y las diversas ramas de las ciencias sociales interesadas en abordar de manera sistemática los impactos causados por la minería a gran escala en las comunidades locales de Colombia.

El presente artículo propone una metodología desde la intersección entre la geografía crítica, la ecología política y la antropología cultural a través del estudio de caso de Boquerón que aborde las siguientes preguntas: ¿cómo deben entenderse y estudiarse los territorios impactados por el extractivismo? ¿Cómo influencian los regímenes de derechos, tenencia y uso de la tierra las relaciones entre la sociedad y la naturaleza? ¿Qué papel juega el capital, el Estado y la tecnociencia en la desterritorialización de las comunidades impactadas por la minería a gran escala? ¿Cómo

26 Escobar, Territorios de diferencia, 79. 
deberían responder el Estado y la academia frente al nuevo desafío del desplazamiento forzado por minería a gran escala en Colombia?

Ya que «la manifestación más interesante de los conocimientos geográficos surge de observar el ordenamiento y la forma espacial en movimiento», pues el espacio debe considerarse un marco dinámico en la constitución de la vida física, ecológica, social y político-económica ${ }^{27}$, este artículo intentará dar una perspectiva interdisciplinar desde las ciencias sociales a los aspectos diacrónicos del territorio de la zona centro del Cesar a través del caso de la comunidad de Boquerón. Comenzaremos en la época de la Colonia con el asentamiento de haciendas en la región durante el siglo XVI, rápidamente tornándonos a la tensión entre los desarrollos latifundistas promovidos por la Constitución Política de 1886 y la simultánea formación de pueblos, como Boquerón, que gozaron por muchos años de sabanas comunales antes de la progresiva parcelación y «empresarización» de la tierra. Al movernos hacia mediados del siglo $\mathrm{xx}$, describiremos cómo las fuerzas de atracción poblacional del dinamismo algodonero y arrocero coexistieron con la actividad ganadera y las formas colectivas de propiedad agraria. Esta situación cambió radicalmente con el comienzo de la explotación carbonífera en 1995 y se agravó con la promoción estatal de la minería a gran escala en 2002, pues significó el desmonte de pequeñas propiedades y el acaparamiento de tierras característico de industrias extractivas como la minería de carbón a cielo abierto. Así, demostraremos que los regímenes de uso, tenencia y aprovechamiento de la tierra dieron vida a Boquerón y ahora lo obligan a abandonar este territorio. Sin embargo, como construcción social, dichos regímenes no son inevitables y pueden ser modificados, especialmente cuando indagamos si la minería realmente justifica el desplazamiento de comunidades que hacen parte del patrimonio cultural de la nación (una verdadera fuente de utilidad pública e interés social).

Para desarrollar estas premisas, dividimos este artículo en tres secciones principales que buscan: 1 )

27 David Harvey, «Identidades cartográficas: los conocimientos geográficos bajo la globalización», en Espacios de Capital: Hacia una geografía crítica, trans. Cristina Piña Aldao (Madrid: Akal, 2007), 241. presentar a Boquerón como lugar, con especial atención a la relación mutuamente constitutiva entre la historia de la región Caribe, los ecosistemas naturales y las prácticas productivas, las festividades y las creencias de la comunidad; 2) establecer cómo los regímenes de tenencia y uso de la tierra a lo largo de la segunda mitad del siglo xx permitieron la desmantelación de algunas de las más representativas prácticas culturales de Boquerón mediante el deterioro progresivo de los ecosistemas que daban sustento a la comunidad; 3) desarrollar algunos lineamientos para motivar a los sectores académicos de historiografía y ciencias sociales para que establezcan un método crítico y multidimensional que estudie los impactos producidos por la minería a gran escala en el país. Al realizar una aproximación teórica al caso de la comunidad de Boquerón en el Cesar intentamos avanzar la idea de que la historización de los lugares construidos por las comunidades locales es una estrategia fundamental para resistir el despojo y el desplazamiento forzado causados por el extractivismo en Colombia.

\section{Boquerón como «lugar»}

\section{El devenir histórico del territorio}

El establecimiento de las poblaciones de Becerril, La Jagua de Ibirico y El Paso constituyó el entorno social e histórico del cual emergió la comunidad de Boquerón. Entender la historia regional permite la comprensión integral del origen, la raíz y las condiciones materiales de las prácticas culturales del corregimiento bajo estudio, muchas de las cuales son fruto del intercambio, la simbiosis y la interrelación constante con los asentamientos aledaños. El devenir histórico de estos poblados ejemplariza la noción técnica de territorio y territorialización, es decir las demarcaciones de fronteras, la espacialización de la inclusión y la exclusión social, y la manifestación del poder político ${ }^{28}$. Sin embargo, en medio de las confrontaciones condicionadas por las formas de ocupación del territorio, las prácticas de vida en estos tres lugares crearon

28 Dietz, «Researching Inequalities», 18. 
las circunstancias para un estrecho mestizaje entre las poblaciones indígenas y afrodescendientes, una interacción étnico-cultural de carácter regional conocida como zambaje que dio luz a sofisticadas expresiones líricas, alimentarias, recreativas y musicales. A continuación presentamos una breve reseña de este contexto histórico para luego abordar Boquerón como lugar.

E1 4 de marzo de 1594 el capitán español Bartolomé de Aníbal Paleólogo Becerra fundó el municipio de Becerril del campo en compañía de 60 hombres que tenían la misión de explorar la región de El Paso del Adelantado y «fundar asentamientos permanentes con categoría de ciudad $»^{29}$. Las familias españolas constituyeron amplias haciendas ganaderas para cuya operación y productividad fue necesaria la importación de mano de obra. Esta dinámica dio origen a asentamientos numerosos de población afrodescendiente, quienes en principio ocuparon la zona en condición de esclavos, y posteriormente como cimarrones libres que crearon espacios propios de vida y relación colectiva. En 1930, los habitantes de Becerril y los pueblos indígenas que atacaban el poblado de forma constante perfeccionaron un acuerdo de paz entre ellos. Estas emergentes condiciones de tranquilidad motivaron una nueva oleada de migración protagonizada por familias procedentes de la parte sur del departamento de la Guajira, quienes después de largos recorridos se establecieron en Cesar y de forma particular en Becerril para adelantar actividades económicas más rentables $^{30}$. A partir de la década de los cincuenta, con el despegue del cultivo y exportación industrial del algodón en el departamento de Cesar, se dio lugar a una migración masiva de personas y familias de todo el país que llegaron a los municipios de la región atraídas por el dinamismo de la economía del algodón ${ }^{31}$.

29 Tomás Darío Gutiérrez, Cultura vallenata, origen, teoría y pruebas (Bogotá: Plaza y Janés, 1992), 131.

30 Gutiérrez, Cultura vallenata, 139.

31 José Gamarra, «La economía del Cesar después del algodón», Documentos de trabajo de economía regional, n. ${ }^{\circ} 59$ (2005), 2122. http:// www.banrep.gov.co/ sites/ default/ files/publicaciones/ archivos/DTSER-59.pdf (consultado el 18 de octubre de 2014).
En el territorio que hoy integra la jurisdicción del municipio de la Jagua de Ibirico ${ }^{32}$, por otra parte, la colonización hispánica estableció un nuevo sistema político sustentado económicamente en la extracción minera de metales preciosos y en el funcionamiento de haciendas ganaderas de uso extensivo de la tierra. Una de las haciendas más sobresalientes, la estancia o hato de Ibiricus, se sustentó principalmente en la mano de obra esclava conducida de las diversas regiones de la costa atlántica a través de puntos de distribución como Valledupar y Mompox. Los afrodescendientes en la Jagua de Ibirico fueron la base del poblamiento, de la producción agrícola y ganadera de la zona. A su vez, El Paso fue la primera hacienda de la Gobernación de Santa Marta creada en la época colonial (una de las primeras haciendas ganaderas constituidas en América Latina y en Colombia) y fue nombrada así por ser uno de los puntos importantes de la ruta que tomó el conquistador Alonso Luis de Lugo en 1544. Allí se instauró un poblado sobre un vasto territorio ancestralmente habitado por pueblos indígenas de ascendencia Tupe-Chimila pero que, con posterioridad, fue ocupado en su mayoría por población afrodescendiente. Varias haciendas de extensión considerable se instalaron con el correr del tiempo en las tierras de El Paso en cuyo interior se erigieron poblados enteros y permanentes de familias zambas y afrodescendientes ${ }^{33}$.

Las formas de ocupación del territorio, así como las prácticas de vida en este lugar, crearon las condiciones para un estrecho mestizaje entre las poblaciones indígenas y afrodescendientes ( $z a m-$ baje). Esta interacción dio lugar a una hibridación cultural que se manifestó en producciones musicales de tipo lírico, instrumental y de expresión corporal. En particular, se ha sostenido que este proceso permitió el nacimiento de producciones culturales novedosas asociadas con la gaita, el tambor y el canto ${ }^{34}$. Específicamente el canto era una herramienta fundamental en la labor del vaquero en la conducción del ganado desde

\footnotetext{
32 La Jagua de Ibirico alcanzó la categoría de municipio independiente en 1979.

33 Orlando Fals Borda, Historia doble de la Costa. Mompox y Loba (Bogotá: El Ancora, 2002).

34 González, «Transformaciones culturales», 42.
} 
las zonas de pastoreo en el centro del Cesar hasta los puntos de exportación de carnes en Santa Marta, en una ruta de tránsito comercial/cultural que pasó a ser intervenida para satisfacer intereses extractivos ${ }^{35}$. En medio de estas poblaciones (Becerril, La Jagua de Ibirico y El Paso), familias afrodescendientes migrantes de Becerril fundaron a Boquerón, un poblado que fungió como punto intermedio, lugar de tránsito y circulación entre estas tres poblaciones, convirtiéndose en receptora y eje comunicante de tradiciones y prácticas de relacionamiento con el territorio.

\section{La construcción dialéctica de Boquerón}

A diferencia de la noción técnica de territorio, el concepto de lugar implica aquellas localizaciones socialmente construidas, coyunturales y llenas de experiencias históricas y significados sociales ${ }^{36}$. Boquerón captura en sí mismo las complejidades del concepto de lugar pues, según las narraciones realizadas por los ancianos del pueblo y algunos de sus descendientes, la comunidad se integró armónicamente siguiendo un conjunto de prácticas de producción, alimentación, recreación, esparcimiento, creencias religiosas y mitos que definieron su forma particular de «ser, saber y hacer» colectivamente ${ }^{37}$. La fundación de Boquerón tuvo dos lugares y momentos de ocupación del territorio: un poblado original que fue levantado en el punto conocido como la Ciénaga, a una distancia de 200 metros de la ubicación actual del corregimiento, y un segundo asentamiento relocalizado por algunos de los primeros fundadores y por sus hijos ${ }^{38}$.

El primer lugar de ubicación de Boquerón fue un punto de convergencia en un camino de herradura que permitía el tránsito de personas y carga al interior de las haciendas ganaderas que cubrían buena parte del territorio que hoy en día integra los municipios de Becerril del Campo, La Jagua de Ibirico y El Paso del Adelantado ${ }^{39}$. A poca

35 Gutiérrez, Cultura vallenata, 390.

36 Dietz, «Researching Inequalities», 18.

37 Ver Escobar, Territorios de diferencia, 48, para el marco teórico general y González, «Transformaciones culturales», para la documentación concreta de estos elementos en Boquerón.

38 González, «Transformaciones culturales», 43.

39 González, «Transformaciones culturales», 43. distancia existía un camino real ampliamente frecuentado que servía de corredor de productos en la ruta El Paso-Codazzi. Con el paso del tiempo, grupos familiares procedentes de distintos parajes se sumaron a la conformación poblacional de la comunidad. Una segunda migración de personas que se integraron a las costumbres y formas de vida de los habitantes que fundaron el poblado se estableció en el corregimiento entre 1930 y $1940^{40}$.

La principal actividad económica de sostenimiento en la zona era el cultivo manual de diversos productos agrícolas del grupo de los almidones. $\mathrm{La}$ agricultura se combinaba con el pastoreo de animales de crianza, mientras que la caza de animales de monte y la recolección de frutas de los árboles cercanos se realizaba para complementar la dieta. La pesca también era una práctica recurrente en los caños y arroyos que rodeaban el poblado, los cuales eran ricos en diversas especies ícticas y sobresalía la presencia abundante de caimanes de aguja y de caimanes porro ${ }^{41}$. Boquerón era surcado en la parte norte por las aguas de los ríos Tucuy y Maracas, y en la parte sur por el caño Paujil. Este último era utilizado por sus habitantes para hacer jornadas diurnas y nocturnas, individuales y colectivas, de captura de peces que permitían no solo la alimentación del pescador y su familia, sino la repartición de los excedentes entre el resto de personas de la comunidad ${ }^{42}$. Ubicados a una distancia más lejana se encontraban los ríos Sororia y Calenturitas, los que también eran visitados para las faenas de pesca ${ }^{43}$.

Las prácticas de sostenimiento económico se fundamentaban en las posibilidades proveídas por el entorno natural e interactuaban con la creatividad humana para la generación de alimentos de compleja preparación. Así, era posible producir platos típicos que constituían la base alimentaria de los habitantes del poblado. Desde desayunos compuestos por arepas de queso y leche cuajada, pasando por almuerzos y cenas que incluían viuda de pescado, sancochos de animales de monte, ajiaco de morrocoy con panela y arroces con

\footnotetext{
40 González, «Transformaciones culturales», 44. 41 González, «Transformaciones culturales», 44. 42 González, «Transformaciones culturales», 44.

43 Anciano pescador de Boquerón, entrevistado por los autores, La
} Jagua de Ibirico, 12 de noviembre, 2013. 
carne cerdo o de res, la dieta se fundamentaba en las posibilidades de acceso a fauna silvestre y animales de ganado ${ }^{44}$. No solo se realizaban preparaciones acordes con las materias primas a las que se tenía acceso, sino que se creaban formas y elementos complementarios que perfeccionaban la preparación de los alimentos. Por ejemplo, la base de cocción de las distintas preparaciones era conocida como «aliño», una mezcla de cebolla, ajo y achiote que enriquecía el sabor de las preparaciones; además, los aceites empleados en la cocina eran elaborados a partir de un corozo de la palma de vino o de grasa de cerdo y los utensilios para realizar las preparaciones eran múcuras elaboradas a base de barro ${ }^{45}$.

A la vez que se preparaban y consumían los alimentos, estas prácticas venían acompañadas de rituales comunitarios y de creencias compartidas que dotaban de significado social la básica y humana necesidad de alimentarse. Los ancianos de Boquerón destacaron que compartir los alimentos sucedía dentro de una lógica de intercambio, interrelación y colaboración, que para ellos estrechaba vínculos afectivos y solidarios. En Semana Santa, por ejemplo, existía una serie de pautas sociales especiales como la prohibición de bañarse después del mediodía porque se corría el riesgo de convertirse en pescado, como lo indicaba la leyenda local ${ }^{46}$. Además, «en esos días, los hombres se dedicaban al oficio de la pesca y las mujeres preparaban platos especiales, uno de ellos a base de tortuga o galápago, el cual se acompañaba de dulces de ñame o de guaímaro para terminar los días» ${ }^{47}$.

Otras prácticas también venían acompañadas de los referentes regionales de la costa Caribe en los ámbitos cultural y religioso ${ }^{48}$. La fiesta de la Virgen de la Candelaria, por ejemplo, se realizaba en Boquerón de manera recurrente todos los

44 González, «Transformaciones culturales», 45

45 Hija de familia fundadora de Boquerón, entrevistada por los autores, Becerril, 16 de octubre, 2012.

46 Grupo focal con ancianos de la comunidad de Boquerón, entrevistados por los autores, Becerril, 17 de octubre, 2012.

47 González, «Transformaciones culturales», 45.

48 Aunque conceptos como región se definan usualmente desde una perspectiva materialista que contempla exclusivamente las características físicas del terreno, el régimen climatológico, los entornos construidos y los límites tangibles, definiciones alternativas deciden priorizar la importancia de sentimientos de pertenencia, modos de vida, recuerdos e historia y comunidades imaginadas. Harvey, «Identidades cartográficas», 243. años el 2 de febrero en respuesta a una creencia colectiva arraigada en la población de Becerril. La devoción por la figura de la virgen data de los primeros años del siglo xx, en particular de las confrontaciones bélicas que se suscitaron en la costa Caribe en el marco de la Guerra de los Mil Días ${ }^{49}$. La leyenda popular cuenta que en los momentos de combates las personas huían hacia las zonas apartadas, llevando consigo la figura de la virgen en espera de amparo y protección ${ }^{50}$. Las entrevistas realizadas con los ancianos de Boquerón nos permitieron concluir que fiestas como esta dinamizaban la vida cultural de la comunidad en torno a ritos, danzas y cánticos, espacios y momentos de encuentro, esparcimiento $y$ estrechez de vínculos afectivos ${ }^{51}$. Todos estos dotaban de sentido de pertenencia, espontaneidad y alegría a la cotidianidad del lugar y surgían de prácticas y creencias enraizadas de la región Caribe continuamente (re)presentadas y (re)actuadas en los municipios aledaños.

La danza del pilón becerrilero era una de las celebraciones más distintivas de Boquerón y estaba estrechamente vinculada con los significantes naturales y significados culturales de las festividades de la costa Caribe. Esta danza constituía una fiesta típica que buscaba representar de manera festiva el procesamiento artesanal del arroz y el maíz por las mujeres ${ }^{52}$. El maíz era un producto central en la dieta de la comunidad que permitía la elaboración de bollos, arepas, tamales, chicha y dulces. El pilón, por su parte, era empleado por las mujeres para triturar y macerar, cuyo empleo suponía la ejecución de movimientos acompasados rítmicamente con el fin de moler el cereal. Así, las mujeres cocineras y que

49 Grupo focal con ancianos de la comunidad de Boquerón, entrevistados por los autores, Becerril, 17 de octubre, 2012.

50 González, «Transformaciones culturales», 48.

51 «Se dice que en una de esas huidas ocurrida un 2 de febrero, la figura de la virgen se cayó justo al lado de Cirilo, el hombre más anciano del pueblo y cuando la levantaron se dieron cuenta que toda su ropa se encontraba agujereada, lo que llenó de temor e incertidumbre a los presentes. No obstante al poco tiempo apareció una mujer de baja estatura que les expresó que nada les pasaría, que estarían bien, y así fue. Este hecho cobró relevancia y significado profundo en la comunidad quienes conmemoraban anualmente su fe. El 16 de julio de todos los años tenía lugar la celebración del Corpus Christi, y en ellas participaban todos los habitantes sin distinción». González, «Transformaciones culturales», 48.

52 González, «Transformaciones culturales», 48-49. 
participaban en la danza eran denominadas "pilanderas». En la fiesta, el pilón se sacaba en la noche del viernes antes de carnaval y se pasaba de casa en casa para que cada familia le pusiera algo de dinero, en señal de buenos augurios y prosperidad. Los hombres se vestían de mujeres y las mujeres se disponían alrededor del pilón en señal de estar en la labor de limpieza del maíz. La música era amenizada con un conjunto de gaitas y tamboras ${ }^{53}$. En pocas palabras, el baile del pilón era un escenario de fortalecimiento comunitario.

Dado que la danza del pilón es una de las tradiciones más representativas de la costa Atlántica, debido a que el maíz y el arroz son productos típicos medulares para la elaboración de preparaciones que han sustentado la alimentación de varias generaciones, esta fiesta ha sido un elemento central para la formación de conciencia e identidad y de subjetividad política ${ }^{54}$ (aunque la danza del pilón becerrilero fuese muy distintiva en Boquerón por incluir cánticos y un ritmo propio que lo diferenciaban de otras expresiones musicales en torno al pilón). Sin embargo, estas celebraciones experimentaron un declive progresivo debido a las restricciones en las posibilidades comunales de acceso, uso y disfrute de la tierra y de los recursos naturales derivadas de la instalación de la propiedad privada como estructura predominante de relacionamiento con el territorio a la largo de finales del siglo xx. Dicho cambio estructural transformó la disposición material de estos recursos (la tierra ahora parcelada y subdividida y los recursos naturales acaparados, contaminados o extinguidos) y dio lugar a nuevos anhelos personales y familiares sustentados en la idea de acumulación de bienes y dinero como sentido de la vida.

Los habitantes de las poblaciones rurales percibieron la llegada de la minería como un foco productivo y generador de desarrollo. Este imaginario favoreció la migración de familias asentadas de forma tradicional en Boquerón hacia los municipios de la Jagua de Ibirico y Becerril, entre

53 Taller de intercambio cultural entre el Consejo Comunitario de Negritudes de Boquerón Casimiro Meza Mendoza y el Consejo Comunitario de la Organización Popular Campesina del Alto Atrato (Cocomopoca) y reconstrucción de prácticas afrodescendientes en Boquerón, Boquerón, noviembre, 2012.

54 Harvey, «Identidades cartográficas», 244 otros destinos. Dichas familias buscaban capacitación, vivienda digna, servicios públicos, diversificación de ocupaciones y fuentes de empleo ${ }^{55}$. Esta percepción es clara en el testimonio de un líder comunitario boqueronero:

En el año 1987 llegó Drummond, fue la primera multinacional que llegó a nuestro territorio. Nosotros, en el momento de la llegada de Drummond, hicimos fiesta, lanzamos cohete, porque fue una alegría total. Los viejos de esa época nos decían: «Hombre, llegó la oportunidad para ustedes los jóvenes, para que tengan una vida diferente, trabajen en una empresa, van a tener un sueldo fijo, van a sostenerse mejor, van a educar sus hijos mejor, y va a ser muy fácil para ustedes» Hoy en día creo que en Boquerón hay dos o tres personas nacidas en Boquerón que trabajan en Drummond, después de veinti y pico de años $[\mathrm{sic}]^{56}$.

No obstante, aunque el imaginario de progreso asociado a la llegada de empresas transnacionales haya sido tan marcado en las etapas iniciales del despliegue minero, varios factores han cambiado las percepciones locales: varias décadas de voracidad carbonífera, daños ecológicos y pasivos ambientales $^{57}$, y la decepción comunitaria por la falta de oferta de empleo (previsible, pues la minería es una industria intensiva en capital y no trabajo humano).

Con el paso de los años, la composición poblacional de Boquerón ha estado sujeta a notables variaciones provocadas principalmente por el conflicto armado que ha afectado a la región y por la operación extractiva a gran escala, que han hecho de la comunidad un lugar de asentamiento de familias tradicionales, pero a su vez de recepción de población flotante, migrantes transitorios y permanentes ${ }^{58}$. Este ha sido un factor decisivo en la alteración de canales y dinámicas de interacción social. González advierte las rupturas en valores comunitarios de solidaridad, confianza, y la

55 Grupo focal con ancianos de la comunidad de Boquerón, entrevistados por los autores, Becerril, 17 de octubre, 2012.

56 Líder de la comunidad de Boquerón, entrevistado por los autores, Valledupar, 26 de agosto, 2014.

57 Fierro Morales y López Camacho, «Aportes a la conceptualización», 170-172.

58 Una situación se ha venido acelerando luego de la orden de «reasentamiento involuntario» decretada por el Estado Colombiano. Ver Miguel Barrios, «La sospechosa explosión demográfica de Boquerón», El Heraldo [Barranquilla], 23 de noviembre, 2014. http:// www.elheraldo.co/cesar/la-sospechosa-explosion-demograficade-boqueron-175012 (consultado el 26 de noviembre de 2014). 
pérdida en frecuencia y sentido de aquellos espacios musicales y religiosos tradicionales de encuentro y esparcimiento, entre ellos la danza del pilón becerrilero ${ }^{59}$. El nuevo tejido comunitario, en contraposición, ha dado vida a nuevos espacios de interrelación y socialización que tienen como eje de articulación prioritaria la exigencia al Estado y a las compañías, la adopción de programas y acciones que permitan atender sus necesidades inmediatas y garantizar sus derechos ${ }^{60}$. Los espacios formales constituidos para concertar el cumplimiento a la orden de «reasentamiento involuntario» han generado flujos de relacionamiento convergente entre todos los grupos sociales de Boquerón ${ }^{61}$. De hecho, se conformó un Comité de Concertación integrado por representantes de todos los sectores de la comunidad, y se convocan asambleas comunitarias ampliadas con fines de socialización de los resultados del proceso.

Aunque este nuevo escenario constituya un desafío común, en donde la prioridad es el planteamiento y la exigencia de derechos dado el desequilibrio de poder entre la comunidad y las corporaciones, ha fijado puntos de encuentro entre los pobladores sobre intereses, luchas y exigencias que, si bien no están libres de tensiones y contradicciones internas, sí han dado lugar a momentos de recreación de significados y valoración de la bistoria, costumbres y prácticas culturales que caracterizaban a Boquerón antes de la llegada de la minería. Nuevas dinámicas de relacionamiento solidario, redes de confianza y comunicación han emergido para sentar bases de acciones de resistencia en medio de la opresión ${ }^{62}$. Como aseguran Hardt y Negri, «cuando aparece lo común como la

59 González, «Transformaciones culturales», basada en sus inferencias provenientes de un grupo focal con ancianos de la comunidad de Boquerón, Becerril, 17 de octubre, 2012.

60 Grupo focal con integrantes del Comité de Concertación del reasentamiento de Boquerón, entrevistados por los autores, Boquerón, 27 de agosto, 2014.

61 Migrantes, familias originarias residentes y no residentes han dinamizado organizaciones comunitarias preexistentes, como la Junta de Acción Comunal, y han creado nuevas organizaciones, como el Consejo Comunitario Afrodescendiente «Casimiro Meza Mendoza», los cuales fungen como círculos internos de debate, construcción de agendas y propuestas para encarar el proceso de reinstalación del poblado.

62 Grupo focal con integrantes del Comité de Concertación del reasentamiento de Boquerón, entrevistados por los autores, Boquerón, 27 de agosto, 2014. base y el objetivo de las luchas -no solo lo común como un elemento dado, como la tierra o los recursos naturales, pero también, y más importante, lo común como resultado, como la redes de las relaciones sociales o las formas de vida», es posible la emergencia de formas y fuerzas alternativas que desafían la opresión de la modernidad ${ }^{63}$.

\section{La «desterritorialización» como impacto de la minería a gran escala}

\section{Los regímenes de tenencia y uso de la tierra}

Para investigar los impactos de la minería de carbón sobre Boquerón desde un enfoque de ecología política, es necesario indagar cómo el conocimiento, el acceso (a) y el control (sobre) los recursos naturales han estado mediados por jerarquías sociales y relaciones de poder ${ }^{64}$. Nuestra hipótesis es que los regímenes de tenencia y uso de la tierra han permitido que se prioricen los intereses mineros o estatales y se restrinja el análisis de las transformaciones territoriales a los aspectos relativos al medio natural, obviándose la relación mutuamente constitutiva entre $\mathrm{co}^{-}$ munidades y la naturaleza. En otras palabras, la estructura de la propiedad de la tierra ha permitido la expansión de la minería transnacional, la cual ha tenido efectos devastadores sobre el lugar (Boquerón), el territorio y la región. Para explicar este fenómeno es necesario identificar dichos regímenes y denotar sus transformaciones en el tiempo, comenzando con los pilares normativos de la era republicana hasta llegar a las prácticas del régimen contemporáneo.

La Constitución Política de 1886 y el Código Civil afianzaron un régimen de derechos sobre la tierra sustentado en el principio de propiedad privada de base latifundista, de transmisión por vía de negocios jurídicos de carácter privado, ocupaciones por extensión de dominios y transmisión por linaje familiar. Estos marcos normativos afianzaron los sistemas de uso y adquisición de la tierra preexistente en la era colonial, sustentada en unidades de apropiación y explotación del

\footnotetext{
63 Traducción libre y sin cursiva en el original. Hardt y Negri, Commonwealth, 117.

64 Dietz, «Researching Inequalities», 10.
} 
territorio, entre ellas haciendas, plantaciones, hatos y minas ${ }^{65}$. Lo anterior permitió la configuración progresiva de una estructura agraria cerrada, jerárquica y excluyente que estableció divisiones insalvables entre propietarios de la tierra, ocupantes y trabajadores rurales ${ }^{66}$.

Las primeras décadas del siglo $\mathrm{xx}$, caracterizadas por el surgimiento de movimientos sociales de base campesina-trabajadora, plantearon entre sus exigencias de transformación política la alteración de la estructura agraria y el reconocimiento de derechos sobre la tierra ${ }^{67}$. Las acciones que emprendieron se tradujeron en presiones efectivas sobre el régimen político del momento que, motivado por la necesidad de apaciguar el clamor de reivindicación, dieron lugar a la aprobación de la Ley 200 de 1936 de reforma agraria, que intentó por vía de disposiciones normativas consagrar medidas para reducir la franja de exclusión imperante en la ruralidad, sin que se alcanzaran cambios considerables ${ }^{68}$. Posteriormente, se emitieron normas asociadas a la ampliación de la frontera agrícola, la adecuación de tierras, la titulación y ampliación de resguardos indígenas y la adjudicación de baldíos ${ }^{69}$. Si bien estas leyes no resolvieron la inequitativa distribución de la tierra, ni rompieron el esquema de grandes propiedades, en ellas se incluyeron ciertas medidas en favor del fomento de economías campesinas basadas en el trabajo familiar y colectivo que respondía a las dinámicas sociales del campo ${ }^{70}$.

Aunque las emergentes normas de ampliación de derechos de acceso a la tierra y las figuras allí contempladas adquieren relevancia al ser puntos formales de ruptura con el esquema concentrado

65 Luis Eduardo Nieto Arteta, Economía y cultura en la historia de Colombia (Bogotá: Ediciones Tercer Mundo, 1962).

66 Pierre Glohodes, Las luchas agrarias en Colombia (Bogotá: Editorial La Carreta, 1974).

67 Miguel Urrutia, Historia del sindicalismo en Colombia (Bogotá: Editorial La Carreta, 1976).

68 Salomón Kalmanovitz, Desarrollo de la agricultura en Colombia (Bogotá: Editorial La Carreta, 1978).

69 Aprobadas por medio de las Leyes 100 de 1944, 135 de 1961, 5 de 1973, 41 de 1993, 70 de 1993, y 160 de 1994.

70 Figuras como la Unidad Agrícola Familiar, las Sabanas Comunales, las Tierras de Comunidades Negras, las Zonas de Reserva Campesina y el Subsidio Integral de Reforma Agraria fueron una puerta de entrada para reconocer los modos de vida y producción de los habitantes de la ruralidad. Darío Fajardo Montaña, «Tierras, poder político y reformas agraria y rural», Cuadernos de Tierra y Justicia, n. 1 (2002): 4-42. y excluyente de propiedad del campo que prevaleció en el país, las dinámicas y consecuencias del conflicto armado son obstáculos que impidieron (e impiden), en la práctica, la reestructuración sustancial del régimen de propiedad y de derechos en la ruralidad. Además, a partir de 2002, el Estado colombiano decidió profundizar políticas económicas sustentadas en la explotación a gran escala de recursos minero-energéticos y en la producción agroindustrial. En esta tarea, el Estado afianzó los derechos de propiedad concentrados en actores privados, entre quienes sobresalen las empresas transnacionales mineras interesadas en el desarrollo de proyectos extractivos.

Para mediados de la década de 2000, la estructura de tenencia, uso y aprovechamiento productivo de la tierra se caracteriza por varios factores. Primero, ocurrió el desmonte de las pequeñas propiedades, minifundios o parcelaciones con capacidad de autoabastecimiento productivo y alimentario; en su lugar se robustecen los esquemas de grandes extensiones de tierra, latifundios, minas a gran escala y plantaciones ${ }^{71}$. Segundo, las formas de economía campesina son subvaloradas política y económicamente, y con estas sus tradiciones, conocimientos colectivos y prácticas culturales asociadas a la tierra; en contraposición, se da prevalencia al uso masivo y la explotación tecnificada de recursos naturales ${ }^{72}$. Esta posición es emblemática de lo que Ulloa ha denominado la geopolitica vertical del subsuelo, la cual tiene «el objetivo de controlar tanto el territorio como lo que hay debajo de él, independientemente de quienes lo habitan». Tercero, se han incrementado las figuras que conducen a la «empresarización» de la propiedad y explotación de la tierra, entre las que sobresalen la formalización de derechos de propiedad sobre predios

71 Programa de las Naciones Unidas para el Desarrollo (PNUD), Colombia rural: Razones para la esperanza. Informe Nacional de Desarrollo Humano 2011 (Bogotá: Offset Gráfico Editores, 2011).

72 Rocío Rubio Serrano, «Los actores políticos frente al agro colombiano», Cuadernos de Tierra y Justicia, n. 8 (2002): 3-53. http:// www.kus.uu.se/CF/Cuaderno_08.pdf. (consultado en octubre de 2014). Ver, también, Astrid Ulloa, «Geopolíticas del desarrollo y la confrontación extractivista minera: elementos para el análisis en territorios indígenas en América Latina», en Extractivismo minero en Colombia y América Latina, ed. Bárbara Göbel y Astrid Ulloa (Bogotá: Universidad Nacional de Colombia/Ibero-Amerikanisches Institut, 2014), 447. 
despojados como consecuencia del conflicto armado (que luego son transferidos a empresas privadas); la realización masiva de expropiaciones administrativas por razones de «utilidad pública» en beneficio de las compañías; la compra directa y apropiación de predios por parte de las empresas; la aplicación de políticas corporativas de reasentamientos poblacionales; y el impulso de reformas legales a la normatividad que incorpora figuras ajenas al sistema de propiedad privada en el campo.

\section{La pérdida de prácticas culturales y la degradación del entorno natural}

La estructura de propiedad de la tierra en el departamento del Cesar entre 1950 y 1979 (antes de la minería) se caracterizó por la coexistencia entre grandes latifundios dedicados a la actividad ganadera y la implementación de cultivos agroindustriales como el algodón y el arroz. Sin embargo, predios fiscales de propiedad del Estado, sin restricciones en su régimen de acceso, uso y tenencia, también eran característicos del departamento y se conocían como sabanas comunales ${ }^{73}$. En estos predios se asentaron o permanecieron comunidades que realizaban producción campesina alimentaria de autosostenimiento, como es el caso de la comunidad de Boquerón. En la década de los sesenta, el Cesar estaba clasificado como un territorio donde predominaba el latifundio tradicional, con excepción de núcleos de producción agroindustrial, zonas de producción de café y economía campesina ${ }^{74}$.

La llegada de las empresas extranjeras con intereses en extracción a gran escala de recursos mineros,

73 Según el Decreto 2031 de 1988, estas eran definidas como «terrenos baldíos planos cubiertos de pastos naturales, los cuales han venido siendo ocupados tradicionalmente con ganados en forma común por los vecinos del lugar». Posteriormente el Decreto 2663 de 1994 prevé en su artículo 35 que constituyen reserva territorial del Estado todos los playones y sabanas comunales existentes en el país. En consecuencia, queda prohibido todo cercamiento y obstrucción de estos terrenos mediante la construcción de cercas, diques, canales, y en general obras que tiendan a impedir su aprovechamiento en forma comunitaria por los vecinos del lugar.

74 León Zamosc, «Transformaciones agrarias y luchas campesinas en Colombia: Una mirada retrospectiva», en Estructuras agrarias y movimientos campesinos en América Latina (1950-1990), coord. Zamosc et al. (Madrid: Ministerio de Agricultura, Pesca y Alimentación, 1996), 86. así como la agudización del conflicto armado fueron factores determinantes en el proceso de limitación física de las propiedades por medio de barreras naturales o artificiales. La instalación de alambres de púas en largas longitudes fue un elemento material y simbólico que estableció una distancia, así como una barrera visible y definitiva al acceso y uso del territorio. Como lo han descrito Svampa y Harvey, la profundización de las políticas extractivistas viene intrínsecamente acompañada de procesos como la mercantilización y privatización de la tierra, la expulsión forzosa de las poblaciones campesinas, la conversión de diversas formas de derechos de propiedad común, colectiva, estatal, etc.- en derechos de propiedad exclusivos y procesos coloniales, neocoloniales e imperiales de apropiación de activos, incluyendo los recursos naturales ${ }^{75}$. Si bien en el Cesar desde tiempos coloniales existían predios y haciendas de propiedad privada con delimitación de linderos y mojones de demarcación, estos límites funcionaban según una lógica de libre acceso, tránsito e incluso uso permitido aunque limitado de recursos naturales disponibles.

La extracción de carbón en el Cesar fue una de las pioneras en la instalación del extractivismo en Colombia. En el país, el extractivismo se caracteriza porque la intensa extracción de recursos para la exportación es llevada a cabo por empresas transnacionales, mientras el Estado asume un papel secundario brindando protección a las inversiones y las exportaciones y recibe bajos niveles de compensación por la explotación mineral ${ }^{76}$. En el departamento, la minería de carbón (bajo este modelo extractivista) ha ocasionado efectos desastrosos según criterios de sostenibilidad y sustentabilidad socioambiental: ha desplazado la actividad agropecuaria, en particular la de subsistencia, además ha promovido la acumulación de tierras, el abandono de las zonas rurales y la

\footnotetext{
75 Maristella Svampa, «Extractivismo en América Latina. El Consenso de los Commodities», Le Monde Diplomatique Edición Colombia, n. 124 (2013); Harvey, «El "nuevo" imperialismo».

76 Eduardo Gudynas, «Extracciones, Extractivismos y Extrahecciones: Un marco conceptual sobre la apropiación de recursos naturales», Observatorio del Desarrollo, n. 13 (2013), 8. http://www. academia.edu/4242453/Extracciones_extractivismos_y_extrahecciones._Un_marco_conceptual_sobre_la_apropiaci\%C3\%B3n_ de_recursos_naturales (consultado el 6 de octubre de 2014).
} 
alteración de los usos del suelo ${ }^{77}$. Estas situaciones superan el ámbito económico y se inscriben en la reconfiguración de las relaciones sociales, culturales y territoriales.

La afectación sobre los ecosistemas que sostenían la agricultura de la comunidad de Boquerón es de especial importancia pues, como se ha visto, la relación mutuamente constitutiva de la comunidad con su entorno natural dio surgimiento a ese lugar y a la comunidad desde finales del siglo XIx. La coincidencia y sumatoria de varios factores interrelacionados explican la pérdida progresiva de la agricultura y del tejido social. Por un lado, extensiones significativas de tierra cultivable, antes empleadas en el desarrollo de actividades productivas de autosostenimiento, han sido concentradas y dedicadas de forma prevalente a la actividad minera, al establecimiento de sembradíos de palma africana, con algunas pocas excepciones de fincas en las que conserva la actividad agrícola o ganadera. Por otro lado, las grandes magnitudes de la extracción minera han generado una significativa reducción de la fertilidad, y la capacidad productiva y regenerativa de las capas superficiales del suelo ${ }^{78}$. Paralelamente a la afectación dramática del medio biótico (aire, agua, coberturas vegetales, fauna y flora $)^{79}$, han surgido fenómenos de erosión, deforestación, acidez excesiva e incluso desertificación, los

77 Véanse Juan David Velasco, «Negociando la tierra: empresas extranjeras, minería a gran escala y derechos humanos en Colombia», Estudios Socio-Jurídicos 16, n. 1 (2014) sobre el acaparamiento de tierras por parte de Drummond; Gamarra, «La economía del Cesar»; Geoamérica, «Programa de aprovechamiento sostenible de carbón en la zona central del Cesar. Aplicando la Evaluación Ambiental Estratégica». http://www.simco.gov.co/pasc/ docs/PASC.pdf (consultado el 17 de junio de 2013).

78 Ver Fierro Morales y López Camacho, «Aportes a la conceptualización», 149.

79 La crisis de la agricultura, el surgimiento de enfermedades congénitas en animales superiores que precipitan su muerte, la desaparición de animales de monte antes apetecidos para las cacerías ante la alteración de sus ecosistemas de vida, la afectación de la recolección ante el descapote de los bosques y, por último, la reducción de las faenas de pesca son factores determinantes que inciden en la ostensible transformación de las prácticas culturales de la comunidad, cuyos modos tradicionales de vida se han visto trastocados de manera profunda. Hoy, Boquerón padece de índices elevados de desnutrición que afectan principalmente a la población infantil. Ver Programa Mundial de Alimentos, Naciones Unidas et al., Informe Conjunto de Misión a las Veredas El Hatillo y Plan Bonito (El Paso), y Boquerón (La Jagua de Ibirico) en el Departamento del Cesar. http://bit.ly/1FkPztK (consultado en octubre de 2014). cuales han disminuido las posibilidades de la actividad agrícola ${ }^{80}$.

Los efectos de estos regímenes de propiedad de la tierra y la expansión del capital mundial a través del extractivismo se han manifestado en Boquerón a través de lo que los volúmenes técnicos de la Contraloría General de la República denominan «conflictos e impactos socioambientales». Sin embargo, el impacto de la minería transnacional sobre Boquerón debe ser entendido desde un enfoque dialéctico que no se restrinja a la noción de impacto o conflicto socioambiental, sino que coloque en el epicentro de análisis la noción de desterritorialización, ya que la degradación del entorno natural necesariamente implica la degradación de las prácticas culturales de las poblaciones afectadas por la contaminación ecosistémica. La desterritorialización implica transformaciones culturales experimentadas por una comunidad a partir de la limitación en el acceso y uso de la tierra y de los recursos naturales, en especial del agua. Para el caso de Boquerón, estas limitaciones han sido impulsadas por las compañías mineras y han contado con el aval del Estado.

Antes de la consolidación de la actividad minera, el agua era tomada de forma directa de los cauces superficiales y subterráneas que circundaban la comunidad de Boquerón, y en tiempo de verano era depositada en piletas para asegurar un acceso permanente y continuo al recurso que facilitara las labores domésticas de limpieza, de preparación de alimentos, de empleo en actividades productivas de sobrevivencia, entre otras. La desviación de los ríos, el vertimiento de sustancias contaminantes, las variaciones en la dirección y la potencia del cauce, provocadas por la extracción carbonífera, generaron una dinámica antes desconocida de uso y acceso al recurso consistente en escasez de agua potable para las actividades de sobrevivencia y la afectación en proporciones considerables de la pesca. Para los actores institucionales y corporativos involucrados en el proceso de extracción minera, el agua es concebida como un recurso que si bien posee múltiples usos posibles y servicios ambientales asociados, su uso

\footnotetext{
80 Ver la estimación de dichas pérdidas en Ministerio de Ambiente, Vivienda y Desarrollo Territorial y Universidad de los Andes, Valoración Económica Ambiental.
} 
y destinación debe ser priorizado a favor de la actividad extractiva ${ }^{81}$. Así, el agua no se concibe como un canal natural transmisor de valores ambientales y culturales de las poblaciones que de ellos dependen, sino como instrumento lucrativo.

\section{Conclusión: la historización del lugar como resistencia a las tecnologías de despojo}

[El reasentamiento de Boquerón] es histórico, si, quedará en la historia, pero también debe quedar en la historia que Boquerón era un pueblo tranquilo y va a quedar sumido en el más profundo de los dolores, porque cambiar uno el sitio de ese entorno en que ha vivido tanto tiempo puede ser donde uno vaya demasiado hermoso, pero esa parte, como te diría, la parte afectiva, es lo imborrable ${ }^{82}$.

La figura del «reasentamiento involuntario» causado por la degradación ambiental producto de operaciones mineras a gran escala exige una reflexión académica desde la historiografía y las distintas ramas de las ciencias sociales, específicamente sobre dos temas fundamentales: primero, sobre la capacidad teórica y práctica de reconstruir el tejido social y cultural perdido como consecuencia de la desterritorialización; segundo, sobre los vacíos que existen en la manera como las instituciones del Estado valoran los impactos producidos por la minería en $\mathrm{Co}^{-}$ lombia y el papel que puede entrar a jugar el sector académico en esta valoración. Particularmente, el papel de la historiografía es entender de forma integral la historia de los diferentes lugares, su importancia como parte del patrimonio nacional y su significado para las comunidades. De igual manera, el papel de las ciencias sociales como la geografía, la antropología y la sociología es complejizar las variables, los sujetos y los objetos de análisis dentro de investigaciones sobre impactos causados por industrias extractivas

81 Según el Centro de Estudios sobre el Desarrollo Económico (CEDE), el uso del agua en la actividad carbonífera del Cesar ha incrementado paulatinamente y de forma geométrica entre 1985 y 2008. Específicamente, el uso del agua por compañías carboníferas en 2008 se aproximaba a los 6 millones de metros cúbicos al año, el equivalente necesario para llenar aproximadamente 2.400 piscinas olímpicas. Ver Ministerio de Ambiente, Vivienda y Desarrollo Territorial y Universidad de los Andes, Valoración Económica Ambiental, 85.

82 Entrevista estructurada con líder de la comunidad de Boquerón, entrevistado por los autores, Valledupar, 26 de agosto, 2014. en comunidades locales ${ }^{83}$. En este esfuerzo, pero sin pretensiones taxativas, exponemos algunos lineamientos sobre estos dos temas.

Para Boquerón, el decreto de reasentamiento implica la reinstalación colectiva del poblado y el pago de indemnizaciones directas por familia. Para 2015, el proceso se encuentra en sus etapas iniciales y la comunidad no ha encontrado ni en el Estado ni en las compañías generadoras del daño respuestas efectivas de garantía y protección de sus derechos ${ }^{84}$. Sobre este asunto, las formulaciones teóricas y el registro documental de la construcción de Boquerón como lugar expuestas anteriormente sugieren que la reinstalación colectiva de Boquerón es una imposibilidad teórica. El desarrollo histórico y socialmente construido de forma dialéctica entre la comunidad y su entorno natural ha sido un elemento constitutivo del poblado. Así, la transferencia de los cuerpos que componen la comunidad hacia un nuevo espacio no podrá nunca equivaler a Boquerón como lugar, pues este nuevo asentamiento carecerá de historia, interdependencia con el entorno natural de ese otro espacio y de significado para quienes componen a la comunidad.

Así, la capacidad teórica y práctica de reconstruir el tejido social y cultural perdido como consecuencia de la desterritorialización debe partir de un análisis concreto de las fuerzas que estructuran el territorio (el capital, el Estado y la tecnociencia) y de los actores involucrados en el proceso (el sector empresarial, las ong y los movimientos sociales). Esto porque las tecnologías de despojo como el «reasentamiento involuntario» buscarán siempre deslocalizar los lugares en perjuicio de la autonomía individual y comunitaria, así que se vuelve inaplazable la identificación de las fuerzas a favor del desarraigo y el potencial de

83 Concretamente, teorizar y desplegar investigaciones cualitativas desde una perspectiva de ecología política y mediante la historización del lugar que permita entender las consecuencias de la desterritorialización para el patrimonio cultural, la salud emocional de las comunidades y su sostenibilidad y autonomía en el corto y largo plazo.

84 Grupo focal con integrantes del Comité de Concertación del reasentamiento de Boquerón, entrevistados por los autores, Boquerón, 27 de agosto, 2014. Para una revisión periodística del proceso ver los detalles más actualizados del proceso en Freddy Oñate Acevedo, «Pueblos desplazados por el carbón», El Pilón [Valledupar], 18 de septiembre, 2014. http://elpilon.com.co/inicio/pueblosdesplazados-por-el-carbon/ (consultado en octubre de 2014). 
los agentes sociales para resistirlas. Por un lado, las tres fuerzas estructurantes utilizan estrategias de deslocalización específicas para cambiar la producción de la localidad en su favor ${ }^{85}$ : el capital, mediante procesos de acumulación (intensificación y ampliación geográfica); el Estado, mediante discursos como el desarrollo y la representación (manifestadas en la noción de «utilidad pública» del subsuelo y la militarización de las áreas mineras) y el diseño e implementación de los regímenes de tenencia y uso de la tierra; y la tecnociencia, mediante discursos economicistas (como los estudios de costo/beneficio o de conservación de la biodiversidad).

El Estado, en particular, ha cumplido un rol crucial en la configuración del corredor minero del Cesar como lugar epicentro del extractivismo. Por tanto, el Estado es un actor provocador de los impactos ambientales, de la transformación del paisaje y de la pérdida de prácticas culturales. Su papel ha consistido en sentar las bases del modelo extractivo, por medio de la aprobación de políticas públicas, marcos normativos y decisiones administrativas que impulsan la explotación corporativa a gran escala. En particular, el Estado ha celebrado los contratos de aporte y concesión minera con compañías privadas que fijan las obligaciones y cláusulas que regulan la explotación por tajo y por empresa y ha promovido la concentración progresiva de la propiedad privada en manos de las compañías. Aprobó y realiza seguimiento con capacidades limitadas y sin mayores requerimientos técnicos a las licencias y planes de manejo ambiental ${ }^{86}$. Además, ordenó el «reasentamiento involuntario» de las comunidades rurales circundantes al corredor minero al constatar daños ambientales con efectos en la salud humana ya que omitió por varias décadas su deber de prevenirlos adecuadamente y de

85 Escobar, Territorios de diferencia, 49. Específicamente, en favor del lucro de las compañías que se genera de la plusvalía del «trabajo social abstracto» y la comercialización de recursos naturales no renovables como el carbón que no pagan compensaciones proporcionales al daño ambiental, social y cultural; y en favor de las rentas del Estado y la imposición de un modelo extractivista de dudosa fundamentación técnica y representatividad democrática.

86 Entendidos como instrumentos administrativos que habilitan la intervención sobre el territorio. cumplir oportunamente el deber de protección de los derechos de los habitantes de la región.

En cuanto a la tecnociencia, la falta de una concepción dialéctica de la geografía de la región y su inadecuada historización de los lugares de las comunidades locales que deben enfrentar los grandes consorcios mineros han permitido la deslocalización de los lugares. En tanto ninguno de los cuatro volúmenes de la Contraloría ha realizado un trabajo cualitativo de historización de los lugares, la producción tecnocientífica de este órgano de control ha carecido de un entendimiento integral del territorio ${ }^{87}$. Un primer paso para que la tecnociencia pueda desligarse de su función deslocalizadora es incorporar técnicas historiográficas que permitan apreciar la complejidad dinámica y cambiante del territorio, las regiones y, sobre todo, los lugares. Así, deja de concebirse el espacio como sitio exclusivo de producción y entra a entenderse como lo describe Arturo Escobar con el concepto de «territorio-región» ${ }^{88}$, es

87 Varios estudios, sin embargo, han apuntado hacia el análisis crítico de los regímenes de tenencia y uso de la tierra en Colombia y sus implicaciones más localizadas respecto de los municipios de donde se extrae el carbón en el Cesar. También han documentado las implicaciones geológicas y los impactos irreversibles de la explotación a cielo abierto y el impacto del polvillo de carbón en la salud humana. Los volúmenes más recientes han cuestionado la transparencia en los sistemas de rendición de cuentas y la compensación que dan las compañías al Estado por las externalidades generadas en Cesar. Rodrigo Negrete, «Derechos, minería y conflictos. Aspectos normativos»; Fernando Vargas, «Minería, conflicto armado y despojo de tierras: impactos, desafíos y posibles soluciones jurídicas»; Mauricio Cabrera y Julio Fierro, «Implicaciones ambientales y sociales del modelo extractivista en Colombia»; Guillermo Rudas y Jorge Espitia, «Participación del Estado y la sociedad en la renta minera»; Jesús Olivero Verbel et al., «Implicaciones de la minería del carbón en el ambiente y en la salud humana: Una aproximación abreviada al estado del arte», en La Minería en Colombia: Derechos políticas públicas y gobernanza, (Bogotá: Imprenta Nacional de Colombia, 2013). Fernando Vargas, «Propiedad sobre el subsuelo y los recursos mineros: aportes comparativos para el caso colombiano»; Guillermo Rudas, «Revisitando el debate sobre renta minera y government take: el carbón a gran escala en Colombia», en Contraloría General de la República, La minería en Colombia: Daños ecológicos y socio-económicos y consideraciones sobre un modelo minero alternativo (Bogotá: Imprenta Nacional de Colombia, 2014). Julio Fierro, «Análisis intersectorial sobre la minería de carbón en el departamento del Cesar: Un enfoque desde la perspectiva del riesgo»; Álvaro Pardo, «Análisis de los contratos de Drummond Limitada en el departamento del Cesar», en Contraloría General de la República, La minería en Colombia: Control público, memoria y justicia socioecológica, movimientos sociales y posconflicto (Bogotá: Imprenta Nacional de Colombia, 2014).

88 Según Arturo Escobar y su estudio etnográfico de los movimientos sociales partícipes en la construcción del Pacífico colombiano como 
decir como el lugar que incorpora el proyecto de vida de una comunidad y la sustentabilidad del territorio, específicamente la sustentabilidad entendida «no en términos de parches o de actividades singulares, o solo en una base económica», sino como idea que responde «al carácter íntegro y multidimensional de las prácticas de apropiación efectiva de los ecosistemas» ${ }^{89}$.

Para el caso de Boquerón, la historización de los valores colectivos de la comunidad (como la solidaridad, la confianza, la colaboración y la importancia de la palabra durante celebraciones como el baile del pilón o las cenas en grupo) apuntaría a que los elementos culturales estaban estrechamente ligados a formas de producción alimentaria autosustentable y autónomas con base en jornadas compartidas de trabajo de la tierra, faenas de pesca, jornadas de cacería y recolección. Esto sugiere que, como argumenta la visión dialéctica de la geografía, la humanidad no es un mero objeto de las fuerzas evolutivas sino que los seres humanos activamente transformamos los entornos en los que vivimos, lo que genera consecuencias esperadas e inesperadas ${ }^{90}$. Una de esas consecuencias (in)esperadas puede ser el aprovechamiento efectivo, eficiente y sostenible de los ecosistemas. Así, entender esta sustentabilidad, fundamentada en las prácticas de «ser, saber y hacer» de las comunidades locales, puede ser crucial en momentos en los que la degradación ambiental por minería avanza a pasos acelerados y los efectos devastadores del cambio climático se empiezan a sentir en la región $\mathrm{Ca}$ ribe $^{91}$. Según los crecientes niveles de contaminación, pronto la materia orgánica, el aire y el agua del centro de Cesar serán irrecuperables y habrá una única función productiva: la minería de carbón a gran escala. Es el momento para que

lugar en la segunda mitad del siglo xx, las prácticas diarias de grupos negros, indígenas y mestizos han construido sus mundos socionaturales en medio de las modernas fuerzas estructurantes del territorio y creado estrategias «basadas-en-lugar» que dependen de la ligazón al territorio y la cultura. Escobar, Territorios de diferencia.

89 Escobar, Territorios de diferencia, 165.

90 Harvey, «La geografía de la acumulación capitalista», 247.

91 Ver «Se viene una sequía devastadora», Semana [Bogotá], 23 de julio, 2014. http://www.semana.com/nacion/articulo/alerta-por-sequia -en-colombia/396628-3 (consultado el 20 de septiembre de 2014); «Sigue agravándose más la sequía en la región Caribe», Portafolio [Bogotá], 23 de julio, 2014. http://www.portafolio.co/economia/sequia -caribe-julio-2014 (consultado el 20 de septiembre de 2014). la academia ahonde nuestro entendimiento sobre los nocivos efectos de la desterritorialización causada por el extractivismo.

\section{Bibliografía}

\section{Fuentes primarias}

Anciano pescador de Boquerón. Entrevistado por los autores. La Jagua de Ibirico, 12 de noviembre, 2013. Grupo focal con ancianos de la comunidad de Boquerón. Entrevistados por los autores. Becerril, 17 de octubre, 2012.

Grupo focal con integrantes del Comité de Concertación del reasentamiento de Boquerón. Entrevistados por los autores. Boquerón, 27 de agosto, 2014.

Hija de familia fundadora de Boquerón. Entrevistada por los autores. Becerril, 16 de octubre, 2012.

Líder de la comunidad de Boquerón. Entrevistado por los autores. Valledupar, 26 de agosto, 2014.

Taller de intercambio cultural entre el Consejo Comunitario de Negritudes de Boquerón Casimiro Meza Mendoza y el Consejo Comunitario de la Organización Popular Campesina del Alto Atrato (Cocomopoca) y reconstrucción de prácticas afrodescendientes en Boquerón. Boquerón, noviembre, 2012.

\section{Fuentes secundarias}

Barrios, Miguel. «La sospechosa explosión demográfica de Boquerón». El Heraldo [Barranquilla], 23 de noviembre, 2014. http://www.elheraldo. co/cesar/la-sospechosa-explosion-demograficade-boqueron-175012

Cabrera, Mauricio y Julio Fierro. «Implicaciones ambientales y sociales del modelo extractivista en Colombia». En Contraloría General de la República, La minería en Colombia: Derechos políticas públicas y gobernanza, 89-124. Bogotá: Imprenta Nacional de Colombia, 2013.

Dietz, Kristina. «Researching Inequalities from a Socio-ecological Perspective». desiguALdades.net International Research Network on Interdependent Inequalities in Latin America, Working Paper n. ${ }^{\circ}$ 74 (2014): 1-35. http://www.desigualdades.net/ Resources/Working_Paper/74-WP-Dietz-Online.pdf?1411372033. 
Escobar, Arturo. Territorios de diferencia: Lugar, movimientos, vida, redes, traducido por Eduardo Restrepo. Popayán: Envión Editores, 2010.

Fajardo Montaña, Darío. «Tierras, poder político y reformas agraria y rural». Cuadernos de Tierra y Justicia, n. 1 (2002): 4-42.

Fals Borda, Orlando. Historia doble de la Costa. Mompox y Loba. Bogotá: El Ancora, 2002.

Fierro Morales, Julio y René López Camacho. «Aportes a la conceptualización del daño ambiental y del pasivo ambiental por minería». En Contraloría General de la República, Minería en Colombia: Daños ecológicos y socio-económicos y consideraciones sobre un modelo minero alternativo, 79-186. Bogotá: Imprenta Nacional de Colombia, 2014.

Fierro, Julio. «Análisis intersectorial sobre la minería de carbón en el departamento del Cesar: Un enfoque desde la perspectiva del riesgo». En Contraloría General de la República, La minería en Colombia: Control público, memoria y justicia socioecológica, movimientos sociales y posconflicto, 43-162. Bogotá: Imprenta Nacional de Colombia, 2014.

Gamarra, J. «La economía del Cesar después del algodón». Documentos de trabajo de economía regional, n. 59 (2005): 1-110. http://www.banrep. gov.co/sites/default/files/publicaciones/archivos/DTSER-59.pdf

Geoamérica. «Programa de aprovechamiento sostenible de carbón en la zona central del Cesar. Aplicando la Evaluación Ambiental Estratégica». http://www.simco.gov.co/pasc/docs/PASC.pdf.

Glohodes, Pierre. Las luchas agrarias en Colombia. Bogotá: Editorial La Carreta, 1974.

Göbel, Bárbara y Astrid Ulloa. «Colombia y el extractivismo en América Latina». En Extractivismo minero en Colombia y América Latina, editado por Bárbara Göbel y Astrid Ulloa, 15-33. Bogotá: Universidad Nacional de Colombia/ Ibero-Amerikanisches Institut, 2014.

Gómez Montes, Ignacio y Maria Luisa Eschenhagen. «Conflictos socioambientales de la minería de oro y el rol del modelo económico dominante en América Latina». En Extractivismo minero en Colombia y América Latina, editado por Bárbara Göbel y Astrid Ulloa, 389-423. Bogotá: Universidad Nacional de Colombia/Ibero-Amerikanisches Institut, 2014.

González, María Ximena. «Transformaciones culturales y territoriales ocasionadas por la minería a gran escala: el caso de la comunidad de Boquerón (Cesar-Colombia)». Tesis de maestría, Pontificia Universidad Javeriana, 2013.

Gudynas, Eduardo. «Extracciones, Extractivismos y Extrahecciones: Un marco conceptual sobre la apropiación de recursos naturales». Observatorio del Desarrollo, n. 13 (2013): 1-18. http:// www.academia.edu/4242453/Extracciones_ extractivismos_y_extrahecciones._Un_marco_ conceptual_sobre_la_apropiaci\%C3\%B3n_de_ recursos_naturales

Gutiérrez, Tomás Darío. Cultura vallenata, origen, teoría y pruebas. Bogotá: Plaza y Janés, 1992.

Hardt, Michael y Antonio Negri. Commonwealth. Cambridge: Harvard University Press, 2009.

Hardt, Michael y Antonio Negri. Imperio. Buenos Aires: Paidós Surcos 3, 2005.

Harvey, David. «El "nuevo" imperialismo: acumulación por desposesión». Socialist Register, n. ${ }^{\circ} 40$ (2004): 99-129.

Harvey, David. «La geografía de la acumulación capitalista: reconstrucción de la teoría marxiana». En Espacios de capital: Hacia una geografía crítica, 255-285. Madrid: Akal, 2007.

Harvey, David. «Identidades cartográficas: los conocimientos geográficos bajo la globalización». En Espacios de capital: Hacia una geografía crítica, traducido por Cristina Piña Aldao, 225-252. Madrid: Akal, 2007.

Kalmanovitz, Salomón. Desarrollo de la agricultura en Colombia. Bogotá: Editorial La Carreta, 1978.

Mançano Fernandes, Bernardo. «Movimentos socioterritoriais y movimentos socioespaciais: contribuçãocontribuição teórica para uma leitura geográfica dos movimentos sociais». Observatorio Social de América LatinaRevista Nera, n. ${ }^{\circ} 16$ (2005). http://revista.fct.unesp.br/index.php/nera /article/view/1460/1436.

Mignolo, Walter. Local Histories/Global Designs. Coloniality, Subaltern Knowledges, and Border Thinking. Princeton: Princeton University Press, 2012. Ministerio de Ambiente, Vivienda y Desarrollo Territorial, Colombia, y Universidad de los Andes. Valoración Económica Ambiental en la Zona Carbonifera del Cesar que comprende los municipios de Becerril, Agustín Codazzi, Chiriguaná, El Paso y La Jagua de Ibirico. Bogotá: Universidad de los Andes, 2010. http://www.colombiapuntomedio. com/Portals/0/Archivos2014/Drummond2014/ 
Valorac_Econ_Amb-Zona_Carb_Cesar_MAVDT.pdf

Negrete, Rodrigo. «Derechos, minería y conflictos. Aspectos normativos» En Contraloria General de la República, La mineria en Colombia: Derechos politicas públicas y gobernanza, 23-54. Bogotá: Imprenta Nacional de Colombia, 2013.

Nieto Arteta, Luis Eduardo. Economía y cultura en la historia de Colombia. Bogotá: Ediciones Tercer Mundo, 1962.

Olivero Verbel, Jesús. et al. «Implicaciones de la minería del carbón en el ambiente y en la salud humana: Una aproximación abreviada al estado del arte». En Contraloría General de la República, La minería en Colombia: Institucionalidad y territorio, paradojas y conflictos, 229-252. Bogotá: Imprenta Nacional de Colombia, 2013.

Oñate Acevedo, Fredy. «Pueblos desplazados por el carbón». El Pilón [Valledupar], 18 de septiembre, 2014. http://elpilon.com.co/inicio/ pueblos-desplazados-por-el-carbon/

Osorio, Camila. «Hay locomotora minera, pero no locomotora para la reubicación de los vecinos». La Silla Vacia [Bogotá], 11 de septiembre, 2011. http://lasillavacia.com/historia/hay-locomotora-minera-pero-no-locomotora-para-la-reubicacion-de-los-vecinos-27427

Pardo, Álvaro. «Análisis de los contratos de Drummond Limitada en el departamento del Cesar». En Contraloría General de la República, La minería en Colombia: Control público, memoria y justicia socioecológica, movimientos sociales y posconflicto, 162-242. Bogotá: Imprenta Nacional de Colombia, 2014.

Programa de las Naciones Unidas para el Desarrollo (PNUD). Colombia rural: Razones para la esperanza. Informe Nacional de Desarrollo Humano 2011. Bogotá: Offset Gráfico Editores, 2011.

Programa Mundial de Alimentos, Naciones Unidas et al. Informe Conjunto de Misión a las Veredas El Hatillo y Plan Bonito (El Paso), y Boquerón (La Jagua de Ibirico) en el Departamento del Cesar. http://bit.ly/1FkPztK.

Rubio Serrano, Rocío. «Los actores políticos frente al agro colombiano». Cuadernos de Tierra y Justicia, n. 8 (2002): 3-53. http://www.kus.uu.se/ CF/Cuaderno_08.pdf.

Rudas G. «Revisitando el debate sobre renta minera y government take: el carbón a gran escala en Colombia». En Contraloría General de la República,
La minería en Colombia: Daños ecológicos y socioeconómicos y consideraciones sobre un modelo minero alternativo, 309-380. Bogotá: Imprenta Nacional de Colombia, 2014.

Rudas Lleras Guillermo y Jorge Enrique Espitia Zamora. «La paradoja de la minería y el desarrollo. Análisis departamental y municipal para el caso de Colombia». En Contraloria General de la República, Minería en Colombia: Institucionalidad y territorio, paradojas y conflictos, 27-82. Bogotá: Imprenta Nacional de Colombia, 2013.

Rudas, Guillermo y Jorge Espitia. «Participación del Estado y la sociedad en la renta minera». En Contraloria General de la República, La minería en Colombia: Derechos politicas públicas y gobernan$z a, 125-176$. Bogotá: Imprenta Nacional de Colombia, 2013.

«Se viene una sequía devastadora». Semana [Bogotá], 23 de julio, 2014. http://www.semana.com/ nacion/articulo/alerta-por-sequia-en-colombia /396628-3

«Sigue agravándose más la sequía en la región $\mathrm{Ca}-$ ribe». Portafolio [Bogotá], 23 de julio, 2014. http://www.portafolio.co/economia/sequia-caribe -julio-2014

Serje, Margarita. «Introducción a los debates sobre procesos y proyectos de reasentamiento». En Los dilemas del reasentamiento, editado por Margarita Serje y Stefano Anzellini, 17-42. Bogotá: Universidad de los Andes, 2012.

Serje, Margarita. El revés de la nación, 2 ed. Bogotá: Universidad de los Andes, 2011.

Svampa, Maristella. «Extractivismo en América Latina. El Consenso de los Commodities». Le Monde Diplomatique Edición Colombia (2013): 30-46.

Urrutia, Miguel. Historia del sindicalismo en Colombia. Bogotá: Editorial La Carreta, 1976.

Ulloa, Astrid. «Geopolíticas del desarrollo y la confrontación extractivista minera: elementos para el análisis en territorios indígenas en América Latina». En Extractivismo minero en Colombia y América Latina, editado por Bárbara Göbel y Astrid Ulloa, 425-458. Bogotá: Universidad Nacional de Colombia/Ibero-Amerikanisches Institut, 2014.

Vargas, Fernando. «Minería, conflicto armado y despojo de tierras: impactos, desafíos y posibles soluciones jurídicas». En Contraloría General de la República, La minería en Colombia: Derechos 
politicas públicas y gobernanza, 57-87. Bogotá: Imprenta Nacional de Colombia, 2013.

Vargas, Fernando. «Propiedad sobre el subsuelo y los recursos mineros: aportes comparativos para el caso colombiano». En Contraloría General de la República, La minería en Colombia: Daños ecológicos y socio-económicos y consideraciones sobre un modelo minero alternativo, 271-308. Bogotá: Imprenta Nacional de Colombia, 2014.

Velasco, Juan David. «Negociando la tierra: empresas extranjeras, minería a gran escala y derechos humanos en Colombia». Estudios Socio-Jurídicos 16, n. 1 (2014): 289-314.

Wallerstein, Immanuel. The Capitalist World Economy: Essays. Cambridge: Cambridge University Press, 1979.

Zamosc, León. «Transformaciones agrarias y luchas campesinas en Colombia: Una mirada retrospectiva». En Estructuras agrarias y movimientos campesinos en América Latina (19501990), coordinado por Zamosc et al., 77-132. Madrid: Ministerio de Agricultura, Pesca y Alimentación, 1996.

Fecha de recepción: 3 de diciembre de 2014

Fecha de aprobación: 10 de abril de 2015

Disponible en línea: 30 de agosto de 2015

\section{Cómo citar este artículo}

González, Ximena y Diego Melo. «Historizar el lugar para resistir el desplazamiento por minería de carbón: una aproximación teórica al caso de la comunidad de Boquerón en el Cesar». Memoria y Sociedad 19, n. 39 (2015): 107-126. http://dx.doi. org/10.11144/Javeriana.mys19-39.hlrd 